\title{
Pendekatan Empiris untuk Estimasi Kerugian Ekonomi dan Dampak Kerusakan Lingkungan akibat Gempabumi di Deli Serdang
}

Teguh Rahayu ${ }^{1,2}$, Agus Purwoko ${ }^{2}$

${ }^{1}$ Badan Meteorologi Klimatologi dan Geofisika, Indonesia

${ }^{2}$ Pengelolaan Sumber daya Alam dan Lingkungan, Universitas Sumatera Utara, Medan, Indonesia

\begin{tabular}{l} 
ARTICLE INFORMATION \\
\hline Received: Maret, 5, 2020 \\
Revised: Maret, 22, 2020 \\
Available online: April,20, 2020 \\
KEYWORDS \\
\hline kerusakan lingkungan, kerugian ekonomi, \\
gempabumi, pendekatan empiris, shakemap \\
CORRESPONDENCE \\
\hline E-mail: ayugraha76@gmail.com \\
\end{tabular}

\begin{abstract}
A B S T R A K
Kerusakan lingkungan dan sumber daya alam bisa diakibatkan oleh kejadian gempabumi. Dampak kerusakan yang dihasilkan akan sangat berpengaruh pada keberlangsungan lingkungan dan pertumbuhan ekonomi suatu wilayah. Dalam hal ini, penelitian berfokus pada Kabupaten Deli Serdang, yang merupakan kota yang dari sisi pertumbuhan ekonomi terus berkembang. Kondisi lain potensi Deli Serdang dari sisi kegempaan sangat dipengaruhi oleh aktivitas patahan lokal. Tujuan penelitian ini untuk melihat dampak kerusakan lingkungan, kerugian ekonomi, dan estimasi kematian akibat gempabumi dengan pendekatan empiris. Dalam penelitian ini, dampak kerusakan lingkungan akibat gempabumi dengan menggunakan Shakemap (peta guncangan). Kerusakan lingkungan yang terjadi adalah tanah longsor di sekitar sumber gempabumi. Hasil kerugian ekonomi dan jumlah kematian dengan pendekatan empiris dan Prompt Assessment of Global Earthquakes for Response (PAGER) yang dihasilkan dalam penelitian ini masuk kategori hijau, yang artinya berkisar pada angka $67 \%$ dari perkiraan ekonomi dibawah $\$ 1$ juta dan $65 \%$ dari angka kematian penduduk.
\end{abstract}

\section{LATAR BELAKANG}

Kerusakan lingkungan dapat diakibatkan dari faktor alam. Adanya bencana alam memberikan dampak yang signifikan terhadap kerusakan lingkungan, pembangunan, dan pertumbuhan ekonomi disuatu wilayah. Indonesia secara umum memiliki tingkat bencana yang bervariasi. Bencana alam yang sering terjadi dapat bersumber dari banjir, tanah longsor, gelombang pasang, puting beliung, kekeringan, kebakaran hutan, gempabumi, tsunami, dan letusan gunung api. Tren kejadian bencana 10 tahun terakhir dapat dilihat pada Gambar 1. Tren kejadian bencana dalam 10 tahun terakhir ini memberikan gambaran umum, bahwa dampak dan resiko bencana di Indonesia sangat perlu untuk diperhatikan, guna perencanaan, pembangunan, dan pengurangan dampak dan resiko bencana yang terjadi. Sinergitas antara lembaga dan kementerian pemerintah dengan masyarakat sangat penting untuk menjaga dan melestarikan lingkungan dalam mengurangi dampak yang ditimbulkan.

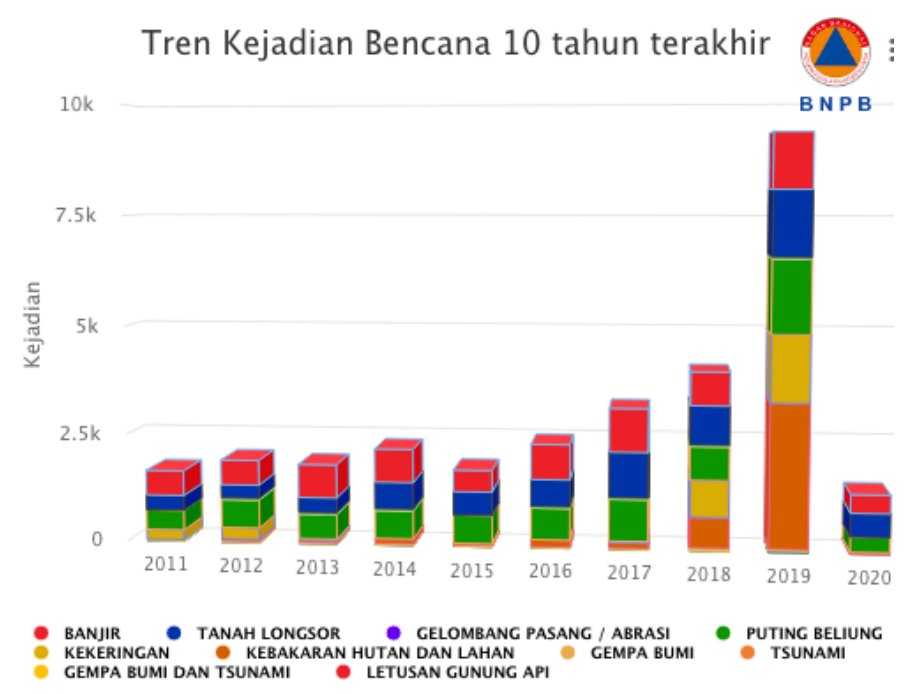

Gambar 1. Tren kejadian bencana 10 tahun terakhir [1]

Kondisi letak geografis Indonesia pada rangkaian cincin api yang membentang sepanjang lempeng Pasifik yang merupakan lempeng paling aktif di dunia memberikan dampak gempabumi sering terjadi. Getaran yang dihasilkan gempabumi secara umum dapat menyebabkan kerusakan fungsi lingkungan hidup bagi manusia dan ruang publik untuk kehidupan, seperti rusaknya struktur jenis tanah, erosi tanah, pencemaran tanah, rusaknya fungsi ekosistem terumbu karang jika pusat gempabumi ada di laut, banyak tanaman yang rusak dan roboh, dan lain sebagainya. 
Dampak lain gempabumi juga berpengaruh pada kerusakan bangunan, kerugian ekonomi pada suatu daerah, kepadatan penduduk, kesehatan, dan sosial ekonomi. Berdasarkan matrik kajian resiko yang dikeluarkan Badan Nasional Penanggulangan Bencana (BNPB) tahun 2015 [2], menunjukkan provinsi Sumatera Utara dengan jumlah penduduk 9.882 .415 jiwa, fisik berkisar Rp49.509.931 dan ekonomi Rp36.531.257. Kondisi ini menunjukkan bahwa tingkat kajian resiko di Sumatera Utara relatif tinggi dari seluruh provinsi di Indonesia. Hal ini didukung dengan potensi gempabumi di Sumatera Utara sangat dipengaruhi oleh aktivitas patahan Sumatera dan patahan lokal di Sumatera Utara.

Penelitian dampak gempabumi terhadap lingkungan telah dilakukan, [3] mengembangkan sistem penilaian lingkungan untuk memeriksa bencana sekunder, evaluasi dampak lingkungan yang komprehensif dilakukan setelah gempabumi. Dampak gempabumi, yang disebabkan oleh getaran tanah juga berdampak pada manusia dan kesehatan [4]. Penelitian dampak gempabumi terus ditingkatkan, sebagai upaya untuk mengurangi resiko kerusakan sumber daya alam, lingkungan dan korban jiwa. Untuk itu diperlukan mitigasi bencana [5]. Di Indonesia, pengurangan resiko kerusakan lingkungan akibat gempabumi menjadi sangat penting, melihat kondisi di Indonesia sering dilanda gempabumi [6].

Penelitian ini berfokus pada kabupaten Deli Serdang yang merupakan salah satu kabupaten di Sumatera Utara. Deli serdang menjadi kota yang pusat perekonomiannya setiap tahun berkembang, hal ini didukung dengan pembangunan fasilitas penerbangan nasional, yaitu Bandara Kulanamu. Dari luas wilayah, Deli Serdang mencapai 2.497,72 h dengan kepadatan penduduk berkisar 2.155.625 jiwa [7]. Kondisi lingkungan di Deli Serdang pada umumnya terdiri dari 3 bidang utama, yaitu hortikultura, kehutanan, dan perikanan. Berdasarkan gambaran di atas, faktor bencana alam, khususnya gempabumi sangat berpengaruh pada kerusakan lingkungan dan valuasi ekonomi di kabupaten ini, melihat kejadian gempabumi di Deli Serdang sangat dipengaruhi oleh aktivitas sesar lokal. Dampak yang ditimbulkan akan sangat beragam dengan kondisi Deli Serdang menjadi kabupaten yang vital dari sisi ekonomi, dan penerbangan di Sumatera Utara. Salah satu dampak dari gempabumi adalah kerusakan lingkungan dalam pertanian dan lahan di Deli Serdang. Perubahan penggunaan dan pengelolaan lahan berlangsung secara dinamis sejalan dengan pertumbuhan jumlah penduduk di suatu wilayah. Pengelolaan lahan untuk kehidupan masyarakat kini seringkali hanya mementingkan kepentingan ekonomi saja tanpa memperhatikan kepentingan jangka panjang, yaitu kelestarian lingkungan. Seiring semakin bertambahnya jumlah penduduk maka lahan pertanian pun semakin berkurang.

Adapun tujuan penelitian ini, untuk melihat dampak kerusakan lingkungan, kerugian ekonomi, dan estimasi kematian akibat gempabumi dengan pendekatan empiris di Deli Serdang.

\section{METODE PENELITIAN}

Dalam penelitian ini, jenis data yang dikumpulkan yaitu data primer dan sekunder. Data primer bersumber dari sumber katalog BMKG yaitu kejadian gempabumi yang dilakukan pada 16 Januari 2017 dengan lokasi gempabumi 3.37 LU dan 98.46 BT, kedalaman $10 \mathrm{~km}$, dan magnitudo 5,6. Data sekunder bersumber dari laporan BNPB, BPS, dan hasil kajian yang sudah dilakukan yaitu jumlah penduduk, luas lahan, dan pertumbuhan ekomomi yang bersumber dari BPS. Hasil kerugian yang bersumber dari BNPB juga menjadi dasar dalam memberikan gambaran dampak dan kerugian yang diperoleh akibat gempabumi. Daerah penelitian berfokus di kabupaten Deli Serdang yang berlokasi tidak jauh dengan ibukota Sumatera Utara yaitu kota Medan.

Metode yang digunakan dalam penelitian ini, dibagi menjadi 2 tahapan, tahapan pertama untuk melihat tingkat atau dampak kerusakan lingkungan di daerah sumber gempabumi dengan menggunakan Shakemap. Tahapan kedua dengan menggunakan pendekatan empiris yaitu loss economy untuk melihat kerugian ekonomi di Deli Serdang dengan menggunakan Prompt Assessment of Global Earthquakes for Response (PAGER). Inti dari sistem PAGER adalah lokasi gempabumi yang tepat waktu dan akurat serta penentuan besarnya yang telah diproduksi USGS selama beberapa dekade. PAGER menggunakan parameter gempabumi ini untuk menghitung taksiran goncangan tanah dengan menggunakan metodologi dan perangkat lunak yang dikembangkan untuk Shakemap. Jumlah orang yang terkena berbagai tingkat goncangan kemudian dihitung dengan menggabungkan peta perkiraan goncangan tanah dengan basis data populasi global Landscan Laboratorium Nasional Oak Ridge National Laboratory. PAGER menghasilkan perkiraan kisaran potensi kematian dan kerugian ekonomi berdasarkan model kerugian spesifik negara yang menjelaskan perbedaan dalam praktik konstruksi dan kerentanan bangunan di seluruh dunia. Selain itu, sistem PAGER memperkirakan potensi tanah longsor yang disebabkan oleh gempabumi, dan jika tersedia, laporan kerusakan dan kematian dari gempabumi bersejarah sebelumnya yang terdekat untuk tujuan perbandingan [8], [9].

Dengan menggunakan perkiraan paparan populasi dan kerentanan infrastruktur lokal, PAGER menentukan ruang lingkup bencana dan memberikan peringatan kepada responden darurat, lembaga pemerintah, dan media. PAGER adalah sistem interaktif. Ketika informasi selanjutnya tersedia, peta yang lebih akurat dari getaran tanah dihasilkan, estimasi halus dari paparan populasi dibuat, dan peringatan terbaru dikeluarkan, jika perlu [10].

Tabel 1. Klustering Tingkat Peringatan, dan Perkiraan Kerusakan dan Kerugian [10]

\begin{tabular}{lll}
\hline Warna dan level Peringatan & Perkiraan Kerusakan/Kematian & Perkiraan Kerugian \\
\hline Merah & $1000+$ & $\$ 1$ milyar \\
Orange & $100-999$ & $\$ 100 \mathrm{jt}-\$ 1$ milyar \\
Kuning & $1-99$ & $\$ 1 \mathrm{jt}-\$ 100 \mathrm{jt}$ \\
Hijau & 0 & $<1 \mathrm{jt}$ \\
\hline
\end{tabular}

Pendekatan Empiris untuk Estimasi Kerugian Ekonomi dan Dampak Kerusakan Lingkungan akibat Gempabumi di Deli 
Pendekatan empiris dengan loss economy dengan persamaan 1.

Loss Ratio $r=\frac{\text { Direct Economic Loss }}{\text { Total Economic Expsure }}$

Dari persamaan (1) diperoleh rasio kerugian ekonomi merupakan total kerugian ekonomi langsung (yang termasuk kerugian struktural, non-struktural, dan konten) yang dinormalisasi dengan paparan ekonomi total [8].

\section{HASIL DAN PEMBAHASAN}

Kejadian gempabumi sangat berdampak dan berhubungan tehadap informasi yang bersumber dari masyarakat pada saat kejadian. Informasi ini yang dapat dikategorikan menjadi skala Mercalli yang membandingkan tingkat kerusakan akibat gempabumi [11], [12]. Berdasarkan kejadian gempabumi yang terjadi pada 16 Januari 2017 di Deli Serdang, kejadian ini terjadi di darat dengan kekuatan gempa 5.6. Dalam hal ini, beberapa wilayah yang merasakan dampaknya seperti Tabel 2.

Tabel 2. Wilayah yang merasakan berdasarkan skala Mercalli

\begin{tabular}{lll}
\hline No & Wilayah & MMI \\
\hline 1 & Sibolangit & VI \\
2 & Medan & IV-V \\
3 & Tebing Tinggi & III MMI \\
4 & Sidikalang & III MMI \\
5 & Pematang Siantar & II MMI \\
\hline
\end{tabular}

Dari Tabel 2 di atas, respon yang didapat dari masyarakat memberikan dampak yang cukup kuat dari kejadian gempabumi di Deli Serdang. Hasil kerusakan dan korban yang diperoleh dari kejadian ini, korban dengan kondisi luka dan meninggal dunia tidak ada, kerusakan pada 7 unit rumah di Desa Kebayaken, dan 1 unit rumah di desa Ujung Payung mengalami kerusakan [13].

Dari hasil penelitian ini, dampak kerusakan lingkungan dapat dilihat dari tingkat intensitas yang diperoleh dari pemetaan dengan Shakemap (Gambar 2). Tingkat resiko gempabumi Deli Serdang pada Januari 2017 menunjukkan spektrum daerah yang terdampak berada pada skala di antara I-V MMI. Intesitas ini memberikan gambaran dengan akurasi kerusakan di sekitar gempabumi mendekati kebenaran. Peta shakemap ini merupakan kombinasi dari dampak dan resiko gempabumi dan digabungkan dengan tingkat populasi kepadatan penduduk dan loss economy.

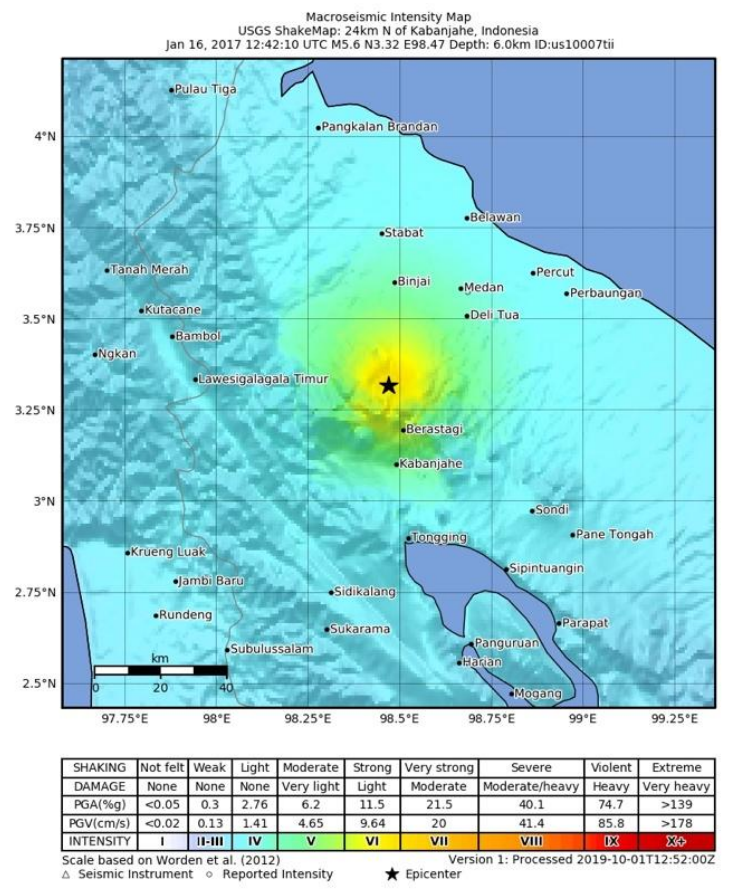

Gambar 2. Shakemap gempabumi 16 Januari 2017 
Estimasi kerugian ekonomi yang diakibatkan gempabumi pada 16 Januari 2017 di Deli Serdang tidak terlepas dari populasi penduduk di daerah gempabumi. Dalam hal ini, dengan pendekatan empiris dengan PAGER, didapat perkiraan kematian yang didasarkan pada populasi penduduk dan kerugian ekonomi.

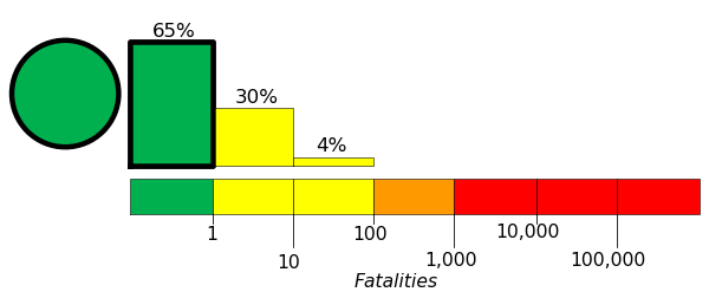

a

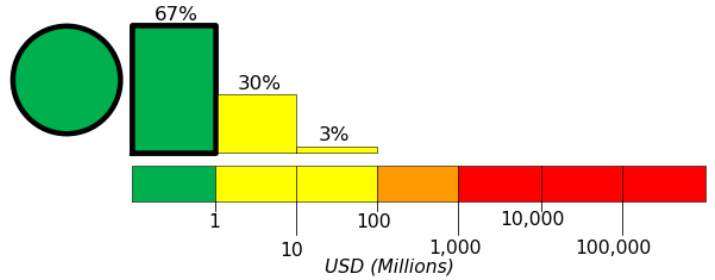

$\mathrm{b}$

Gambar 3. Estimasi kematian dan kerugian ekonomi akibat gempabumi Deli Serdang, 16 Januari 2017

Gambar 3 merupakan hasil perhitungan yang didasarkan pada peringatan warna hijau untuk kematian terkait guncangan (Gambar 3.a) dan kerugian ekonomi (Gambar 3.b). Ada kemungkinan korban dan kerusakan rendah. Perkiraan kematian berada pada hijau, dengan 65\% dengan jumlah penduduk 0, kuning 30\% dari 1-99 jumlah penduduk. Kerugian ekonomi diperkirakan 67\% dari nilai dibawah $\$ 1$ juta, dan $30 \%$ dari $\$ 1$ juta - \$100 juta.

Estimasi paparan populasi terhadap gempabumi di Deli Serdang, dapat dilihat pada Gambar 4.

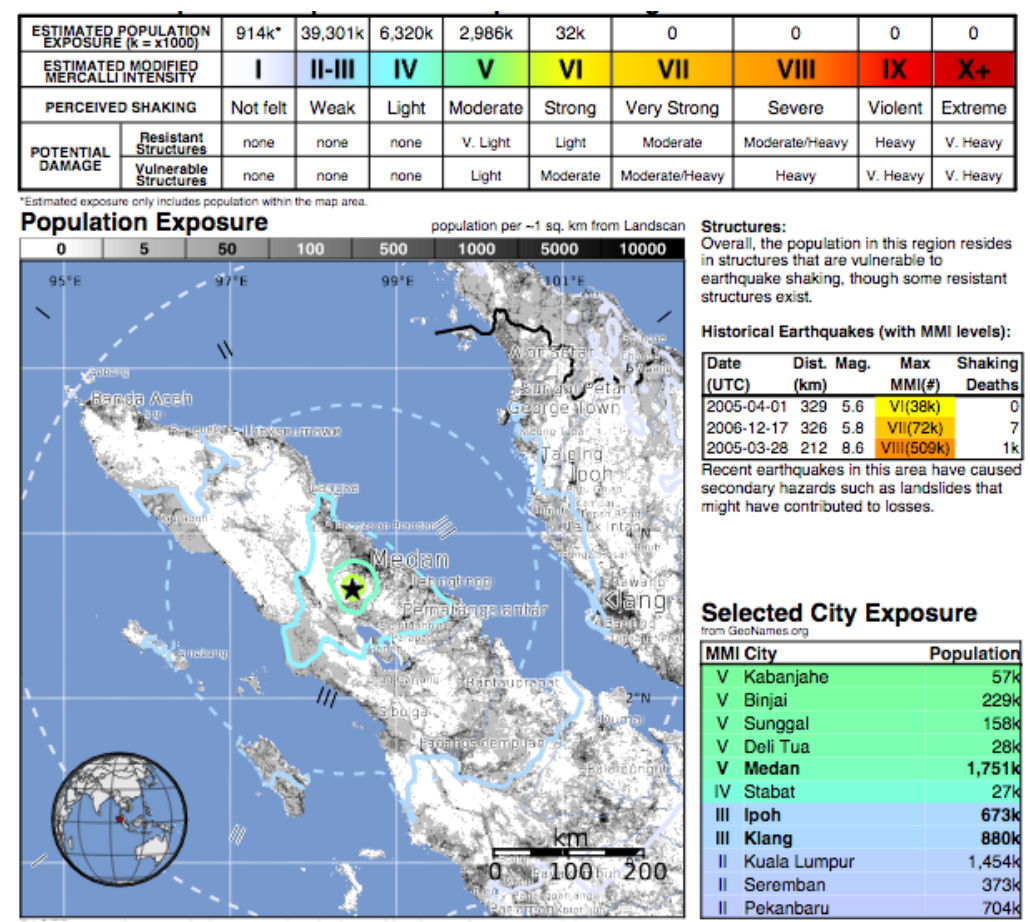

Gambar 4. Perkiraan paparan populasi terhadap gempabumi

Secara keseluruhan, populasi di wilayah ini berada di struktur yang rentan terhadap goncangan gempabumi, meskipun ada beberapa struktur yang resisten. Gempabumi yang terjadi di Deli Serdang ini juga mengakibatkan kerusakan lingkungan yang menyebabkan bahaya sekunder seperti tanah longsor yang berkontribusi terhadap kerugian di daerah sekitar gempabumi.

\section{KESIMPULAN}

Kerusakan lingkungan dan kerugian ekonomi yang disebabkan gempabumi menjadi sangat penting, melihat pertumbuhan ekonomi dan pembangunan infrastruktur dan kelestarian lingkungan perlu untuk dijaga untuk mengurangi dampak resiko yang besar. Kerusakan lingkungan akibat gempabumi dalam penelitian ini menimbulkan terjadinya longsor di daerah sekiar gempabumi, dan kerugian ekonomi yang diperoleh berdasarkan estimasi rasio kerugian cukup rendah (level warna hijau) berkisar 67\% yaitu dibawah $\$ 1$ juta. 


\section{REFERENCES}

[1] "Data Informasi Bencana Indonesia (DIBI).” [Online]. Available: https://bnpb.cloud/dibi/laporan5a. [Accessed: 11-Apr2020].

[2] R. B. Indonesia, "Risiko bencana indonesia."

[3] P. Du et al., "Environmental risk evaluation to minimize impacts within the area affected by the Wenchuan earthquake," Sci. Total Environ., vol. 419, pp. 16-24, 2012.

[4] S. Mavroulis, M. Mavrouli, E. Lekkas, and A. Tsakris, "Impact of earthquakes and their secondary environmental effects on public health," vol. 19, no. 11, p. 3884, 2017.

[5] "Earthquake - Methods of reducing earthquake hazards | Britannica." [Online]. Available: https://www.britannica.com/science/earthquake-geology/Methods-of-reducing-earthquake-hazards. [Accessed: 11-Apr2020].

[6] D. Sungkawa, "Dampak Gempa Bumi Terhadap Lingkungan Hidup,” J. Geogr. Gea, vol. 7, no. 1, 2016.

[7] "Badan Pusat Statistik Kabupaten Deli Serdang." [Online]. Available: https://deliserdangkab.bps.go.id/subject/40/gender.html\#subjekViewTab3. [Accessed: 10-Apr-2020].

[8] K. Jaiswal and D. J. Wald, "Estimating economic losses from earthquakes using an empirical approach," Earthq. Spectra, vol. 29, no. 1, pp. 309-324, 2013.

[9] K. Jaiswal, D. Wald, and K. Porter, "A global building inventory for earthquake loss estimation and risk management," Earthq. Spectra, vol. 26, no. 3, pp. 731-748, 2010.

[10] "PAGER Scientific Background.” [Online]. Available: https://earthquake.usgs.gov/data/pager/background.php. [Accessed: 11-Apr-2020].

[11] Skala MMI (Modified Mercalli Intensity). Badan Meteorologi, Klimatologi, dan Geofisika.

[12] "Skala mercalli - Wikipedia bahasa Indonesia, ensiklopedia bebas." [Online]. Available: https://id.wikipedia.org/wiki/Skala_mercalli. [Accessed: 11-Apr-2020].

[13] BMKG, "Katalog Gempa Bumi Signifikan,” 2019. 